\title{
The Methodology of Simple Comparisons as a Replacement for Comprehensive Benchmarking in Controlling
}

\author{
Pavel Rousek ${ }^{1 *}$, Simona Hašková ${ }^{1}$ \\ ${ }^{1}$ Institute of Technology and Business, School of Expertness and Valuation, Okružní 517/10, 37001 \\ České Budějovice, Czech Republic
}

\begin{abstract}
The paper aims to define an alternative to the traditional process of comprehensive benchmarking in controlling. Traditional benchmarking offers invaluable outputs, but the cost is a high process, time, and cost. The newly defined method of simple comparisons is less demanding from a process, time, and financial point of view, but the accuracy of the results is lower.
\end{abstract}

Key words: benchmarking, controlling, replacement

\section{Introduction}

The aim of this paper is a simplification of the traditional benchmarking process, which is complicated, lengthy, expensive, and, moreover, often difficult to interpret. This paper seeks for a method which is simpler, shorter, cheaper, and easier to interpret.

The character of contemporary economic systems can be described as adaptive depending on changes and effects of microeconomic and macroeconomic factors [1]. Growing global competition helps to liberalize national economies; therefore, companies need to set the quality of their products and services above the competition, to use better technologies than their competitors and to manage their costs below competition [2]. In other words, many companies have to try to be better, faster and cheaper than their competitors [3].

General strategic business practices are based primarily on vision, mission, values and management style [4]. What follows are the respective analyses of the internal and external environment of the organization [5]. The purpose of the analysis is to identify the internal potential of the organization and the market challenges arising from relationships with stakeholders and the trends of the market macro-environment. The strategic framework identifies the key factors to be analysed [6]. To collect the information needed for analysis, the organization uses a management information system, which consists of an internal information system and an external information system. A variety of methods and procedures are used for sorting and analysing information, with basic methods including gap analysis, SWOT analysis, benchmarking, Porter's five market forces model, Ansoff market-products matrix, General Electric matrix, Boston Consulting Group matrix, etc. [7].

\footnotetext{
${ }^{*}$ Corresponding author: rousek@mail.vstecb.cz
} 
This paper focuses on the benchmarking method, which is understood as a catalyst for improvement and innovation [8]. It is a tool to support the development of critical areas of business and management to achieve or exceed set goals based on learning from best practices and understanding the processes to achieve these goals.

A comparative literature survey showed that there are different types of benchmarking and many process tests models [9]. In some cases, the model has been uniquely developed to perform a particular type of benchmarking, which may present problems as confusion among users about whether they should use only a unique benchmark model that has been developed for a particular type or whether use any model for any type of benchmarking; from the user's perspective, it may be difficult to choose the best model from the available models for the purpose given as each model differs in terms of the number of phases involved, the number of steps involved, the application, etc. [10]. Gurumurthy and Kodali [11] analysed the basic benchmarking classification schemes and thus the unique benchmarking models that are developed for each type. The conclusions of the analysis led the authors to design a universal benchmarking model that can be used for all types of benchmarking. The limitation of the model represents its general highly conceptual framework, which can lead to erroneous conclusions without previous verifying its usefulness in practice.

\subsection{Benchmarking}

According to Eschenbach and Siller [12] benchmarking is a continuous process of comparison of our products, services, processes, methods with the best products, services, processes, methods. The data for the benchmarking process comes from Activity-Based Costing and Activity-Based Management. Successful benchmarking leads to improved competitiveness or the competitive position of the organization.

The purpose is to introduce competition which should lead to improvement. This can reveal emerging differences (common and different features) and propose measures to increase efficiency and effectiveness. This method is based on the experience of others and promises a valuable explanation of the differences in performance, processes, and costs.

Types of benchmarking according to Bengt and Östblom [13]:

- Internal benchmarking is performed within a single enterprise between individual business processes, products or functions.

- External benchmarking seeks to compare and measure with another business, providing the opportunity to learn from the best in the same industry.

- Strategic benchmarking is used to improve the overall performance of an enterprise by examining a long-term strategy.

- Process benchmarking is used to make more effective use of a given process or activity within an enterprise.

- Performance benchmarking is used to determine the position of an enterprise by comparing the performance characteristics of services with other enterprises.

- Functional benchmarking is used by businesses to compare with its competitors in the industry.

\subsection{Basic Benchmarking Parameters}

The basic parameters of benchmarking should be thoroughly considered and analysed during the preparation and analysis:

- Objects: Products, services, processes, methods, structures, strategies, activities

- Target values, parameters: Performance, cost, quality, customer satisfaction, process time, storage time 
- Comparative entities, partners: Other departments, other business segments, competitors, improved business

\subsection{Advantages and Disadvantages of Benchmarking}

Eschengach and Siller [12] present the basic advantages and profits of benchmarking:

- Use for analysis, planning, control, communication.

- Benefits of competition.

- New impulses form best practice.

- Comparing actual status and potential for improvement.

- More focus on market requirements.

Eschengach and Siller [12] present the basic disadvantages and risks of benchmarking:

- Ensuring comparable conditions to allow a proper comparison.

- Difficult to obtain detailed information about the competition.

- Time-consuming process.

- Bad results are unwelcome.

A prerequisite is that the entire process must be cost-effective. The benefits of benchmarking must exceed the cost of benchmarking. This paper aims to reduce the cost of benchmarking, reduce the consumption of time, and reduce the consumption of other resources.

\subsection{Benchmarking Code of Ethics}

The ethical context of benchmarking should be addressed in the Code of Ethics, as the benchmarking process will reveal a lot of sensitive information. APQC has developed a Benchmarking Code of Conduct defining the basic moral, ethical and legal bases of benchmarking [14]:

1. Principle of Legality.

2. Principle of Exchange.

3. Principle of Confidentiality.

4. Principle of Use.

5. Principle of Contact.

6. Principle of Preparation.

7. Principle of Completion.

8. Principle of Understanding and Agreement.

\subsection{Cost Benchmarking}

Cost benchmarking is a special form of benchmarking which aims to identify potential areas for improvement in overhead costs

Continuous efforts to compare the costs of the value-added chain with the best companies, identify the causes of the differences, and introduce corrective actions. It is one of the basic cost management tools applied in current business practice. This is a special form of benchmarking where costs are tracked along the entire value chain. In addition to cost items, the relevant process steps of the best-in-class enterprise are determined. It also aims to identify the potential for improvement in overheads. 


\section{Data and Methods}

Practical experience with benchmarking methods, theoretical knowledge summarized in the above literary research, experience with teaching these methods to university students and feedback from these students were used to create this paper.

Interim conclusions were compared with real data from the Czech environment. These interim conclusions were verified based on financial statements (balance sheet, profit and loss account, cash flow) from the financial statements of selected companies.

\section{Results}

\subsection{Simple Comparisons}

A simplified process of the simple comparisons with omitted phases, which, while increasing the accuracy, complicate its execution:

Phase 1: Determining the comparison object

Basic comparison object is determined by what improvement should be made. Areas for improvement vary from products and services, through processes and methods to organizational structure etc.

Phase 2: Setting of target values

Quantitative parameter for the selected object and its target values needs to be set. Depending on the object, the quantitative parameter can be performance, cost, quantity, customer satisfaction, process time, storage time, etc.

Phase 3: Selection of comparative entities

Three basic examples of comparative entities are described below: market leader, market average and macroeconomic average.

Phase 4: Data analysis

The analysis of own data is performed as well as the analysis of data of comparative entities.

Phase 5: Identification of differences

Outputs of the previous phase (own results and comparative entity results) are compared, differences are identified, and their causes are found.

Phase 6: Implementation of measures

Negative differences are critically examined to eliminate these gaps. The proposed measures are implemented.

\subsection{Comparisons to the Market Leader}

If there is an indisputable leader in a specific market, it is advisable to learn from it. An example of such a leader is Apple for the smartphone industry, Google for internet search engine, Amazon for retail, Coca-Cola for soft drinks market, McDonald's for fast food restaurants, etc. 
The advantage of this approach is the comparison to a specific entity, a specific company that is the best in its industry and learning from the best practice. The disadvantage is the potentially complicated acquisition of data on selected companies.

\subsection{Comparisons to the Industry Average}

If there is no clear pattern from which to learn, it is appropriate to compare the data to the industry average. This data is available through various applications, aggregation software, and aggregated databases.

The advantage of this solution is clear data availability. The disadvantage is the financial and time-consuming data acquisition. It is also necessary to change the interpretation of results. Instead of learning from the best enterprise, it is a comparison with an imaginary average enterprise. So, we cannot learn from the average, but we try to overcome the average.

\subsection{Comparisons to the Macroeconomic Average}

There are situations where a comparison with both the market leader and the market average is problematic. This is an example of monopoly markets where the analysed company is both a market leader and the only competitor. Then it is necessary to use the average data at the macroeconomic level.

The key advantage is the potential use in any situation. The main disadvantage is that the analysed company is being compared to an entity that is virtually created and far from the original company (different industry, different size, and different parameters).

\section{Conclusions}

Traditional benchmarking is a very beneficial discipline that uses best practice. Benchmarking outputs are therefore very valuable. On the other hand, the traditional benchmarking process is very complicated, lengthy, expensive, and often difficult to interpret. Simple comparisons seek to eliminate these disadvantages.

The simplification of the process creates an inseparable disadvantage, which is too much simplification of reality. This should be borne in mind when interpreting the results.

Therefore, the presented method of simple comparisons does not attempt to replace traditional benchmarking in its complexity. Rather, it seeks to complement a similar methodology for cases where we prefer simplicity, low-time, and low-budget instead of accuracy.

The goal of the paper was fulfilled. The methodology of simple comparisons as a replacement for comprehensive benchmarking was proposed. The alternative to the traditional process is defined. The newly defined method of simple comparisons is less demanding from a process, time, and financial point of view.

\section{References}

1. M. Dudin, N. Lyasnikov, A. Kuznecov, I. Fedorova, Innovative transformation and transformational potential of socio-economic systems. Middle East Journal of Scientific Research, 17(10), 1434-1437 (2013)

2. Z. Mohamed. Effective management of benchmarking projects. Routledge (2010)

3. A. McAfee, E. Brynjolfsson, T. H. Davenport, D. J. Patil, D. Barton, Big data: the management revolution. Harvard business review, 90(10), 60-68 (2012) 
4. P. Mirvis, B. Googins, S. Kinnicutt, Vision, mission, values. Organizational Dynamics, 39(4), 316-324 (2010)

5. J. Gausemeier, A. Fink, O. Schlake, Scenario management: An approach to develop future potentials. Technological Forecasting and Social Change, 59(2), 111-130 (1998)

6. G. Von Krogh, I. Nonaka, A. Manfred, Making the most of your company's knowledge: a strategic framework. Long range planning, 34(4) 421-439 (2001)

7. M.M. Helms, J. Nixon. Exploring SWOT analysis-where are we now? A review of academic research from the last decade. Journal of strategy and management, 3(3), 215$251(2010)$

8. S. Talluri, A benchmarking method for business-process reengineering and improvement. International Journal of Flexible Manufacturing Systems, 12(4), 291-304 (2000)

9. D. Madsen, K. Slåtten, D. Johanson. The emergence and evolution of benchmarking: a management fashion perspective. Benchmarking: An International Journal, 24(3) 775805 (2017)

10. D.T. Zurell, J. Pagel, J.S. Cabral, T. Münkemüller, D. Gravel, S. Dullinger et al., Benchmarking novel approaches for modelling species range dynamics. Global change biology, 22(8), 2651-2664 (2016)

11. A. Gurumurthy, R. Kodali, Benchmarking the benchmarking models. Benchmarking: An International Journal, 15(3), 257-291 (2008)

12. R. Eschenbach, H. Siller. Profesionální controlling: Koncepce a nástroje [Professional controlling: Concepts and tools]. $2^{\text {nd }}$ edition. Prague: Wolters Kluwer (2012)

13. K. Bengt, S. Östblom. Benchmarking: Jak napodobit úspěšné [Benchamarking: How to imitate successful]. $1^{\text {st }}$ edition. Prague: Victoria Publishing (1995)

14. J. Nenadál, Měrení v systémech managementu jakosti [Measurement in quality management systems]. $2^{\text {nd }}$ edition. Prague: Management Press (2004) 